\title{
Assessment of Cytogenetic Instability and Gene Transcription of Chronic Myelogenous Leukemia Cells Exposed to Non-thermal Plasma Elhadary AMA ${ }^{1}$, El-Aragi $\mathbf{G M}^{2}$, Ahmed MM $^{3 *}$ and Said $\mathbf{Z S}^{4}$
}

${ }^{1}$ Department of Biological Application, Nuclear Research Center, Atomic Energy Authority, Cairo, Egypt ${ }^{2}$ Department of Plasma, Nuclear Research Center, Atomic Energy Authority, Cairo, Egypt

${ }^{3}$ Department of Radiation Biology, National Center for Radiation Research and Technology (NCRRT), Nasr city, Egypt

${ }^{4}$ Department of Radiation Safety, Nuclear and Radiological Regulatory Authority (NRRA), Nasr city, Egypt

\begin{abstract}
Background: This study investigates the effect of Atmospheric Pressure Plasma Jet (APPJ) on cytogenetic instability and transcription of genes associated with propagation of chronic myelogenous leukemia (CML).

Material and methods: Blood samples were collected from six patients with CML and compared with control group. The first three cases were in accelerated phase (AP-CML) resistant to imatinib and nilotinib drugs. The others partially responded and returned to chronic phase (CP-CML). Triple blood cultures for each case were exposed to single dose of plasma, with treatment times of 40,80, and 120 sec. Mitotic phases, indices and abnormalities, as well transcription levels of P53, caspase- 3 and BcL-2 genes were detected before and after plasma jet exposure.
\end{abstract}

Results and conclusion: The data showed that the exposure to APPJ caused remission of the mitotic indices and give a significant increase in the arresting of chromosome instabilities by induction of different mitotic checkpoints and express of sticky and condensed chromosomes which ended by apoptosis and necrosis processes. Additionally, the same events detected for the transcriptional levels of P53, caspase- 3 and Bcl-2 genes.

Keywords: Plasma jet; Mitotic abnormalities; P53; Caspases-3; B-cl2; CML

\section{Introduction}

Next to solid, liquid and gaseous state, physical plasma is referred to as the fourth state of matter. Plasma is generated by the input of sufficient energy (beams, thermal or electric field energy) to the gas that atoms collide with each other and knock their electrons off. It is defined as an ionized gas with quasineutral characteristics [1]. Plasma has a complex composition. It consists of ions, electrons, exited and neutral atoms, free radicals (ROS and RNS), ultraviolet (UV), thermal and infrared radiation, electric fields and molecules [2]. Therapeutic application of plasma at or in the human body is a challenge both for medicine and plasma physics [3].

Non-thermal atmospheric pressure plasma has drawn more and more attention worldwide in the biomedical sector over the last two decades. Plasma effects on mammalian cells are of basic interest in vitro tests to characterize plasma-cell interactions should include the basic cellular parameters like morphology, viability or proliferation and the cellular responses like influence on DNA or cellular proteins [4]. Moreover, the plasma acted at the cellular level to remove diseased tissue without inflammation and damage, to suppress infectious and to modulate the viability (apoptosis/necrosis) of tumoral cells [5].

CML is a prototypical stem cell malignancy with a natural course of progression from an initial CP to AP and blast crisis (BC). Transformation to $\mathrm{BC}$ is associated with acquisition of additional chromosomal aberrations beyond the underlying $\mathrm{t}$ (9:22) chromosomal translocation that characterizes CML [6].

Nilotinib is pharmacological related to imatinib mesylate and dasantinib, these drugs are inhibitors of Bcr-Abl tyrosine kinase. Imatinib resistance can be defined as lack of complete hematologic response in patients with CP-CML, or as a failure to return to $\mathrm{CP}$ for patients with $\mathrm{CML}$ in $\mathrm{AP}$ or $\mathrm{BC}$. Drug resistance is associated with reactivation of $\mathrm{Bcr}-$ Abl signal transduction [7].

Chromosomal aberrations can occur spontaneously or after exposure to genotoxic exposures and play an important role in cancer pathogenesis [8]. Acquisition of chromosomal aberrations is a major feature of disease progression in myeloproliferative and myelodysplastic disorders and acute myeloid leukemia [6]. Ectopic repair between DNA sequences in different chromosomes may result in translocations and dicentric chromosomes [9].

As well, for the last 30 years, chromosome aberration assay and detection of unstable aberrations, dicentrics and acentric fragments, have been used for the estimation of genome damage caused by physical and chemical clastogens [10].

Dicentric chromosomes have been identified as instigators of the genome instability associated with cancer, but this instability is often resolved by one of a number of different secondary events. These include centromere inactivation, inversion, and intercentromeric deletion. Deletion or excision of one of the centromeres may be a significant occurrence in myeloid malignancy and other malignancies but has not previously been widely recognized. The failure to identify centromere deletion in cancer cells until recently can be partly explained by the standard approaches to routine diagnostic cancer genome analysis, which do not identify centromeres in the context of chromosome organization [11].

Mitotic index is defined as the ratio between the numbers of cells in a population undergoing mitosis to the number of cells not undergoing

*Corresponding author: Ahmed MM, Department of Radiation Biology National Center for Radiation Research and Technology (NCRRT), Nasr city, Egypt, Tel: 00202 6713144; E-mail: mahmoud_70mohameds@yahoo.com

Received August 02, 2015; Accepted September 04, 2015; Published September 06, 2015.

Citation: Elhadary AMA, El-Aragi GM, Ahmed MM, Said ZS (2015) Assessment of Cytogenetic Instability and Gene Transcription of Chronic Myelogenous Leukemia Cells Exposed to Non-thermal Plasma. J Cytol Histol 6: 371. doi:10.4172/21577099.1000371

Copyright: (C) 2015 Elhadary AAM, et al. This is an open-access article distributed under the terms of the Creative Commons Attribution License, which permits unrestricted use, distribution, and reproduction in any medium, provided the original author and source are credited. 
Citation: Elhadary AMA, El-Aragi GM, Ahmed MM, Said ZS (2015) Assessment of Cytogenetic Instability and Gene Transcription of Chronic Myelogenous Leukemia Cells Exposed to Non-thermal Plasma. J Cytol Histol 6: 371. doi:10.4172/2157-7099.1000371

mitosis. The purpose of the mitotic index is to measure cellular proliferation. The mitotic index is an important prognostic factor predicting both overall survival and response to chemotherapy in most types of cancer [12].

The cell cycle control system is arrested when cells detect DNA damage. Meanwhile, the premature onset of mitosis leads to another type of cell death that is mitotic catastrophe [13]. Mitotic catastrophe occurs either during or after mitosis [14]. A new type of cell death that takes place at metaphase is defined as metaphase fragmentation where condensed chromosomes lose viability and are progressively degraded [15]. Chromosome fragmentation does not exhibit the typical oligosomal DNA degradation of apoptosis [16]. Cell death is the consequence of inappropriate cell development with different paths. So, it was proposed that hyperplasia could result from decreased apoptosis rather than increased mitosis [17].

The P53 tumor suppressor limits cellular proliferation by inducing cell cycle arrest and apoptosis in response to cellular stresses such as DNA damage, hypoxia, and oncogene activation, many apoptosis-related genes that are transcriptionally regulated by P53 have been identified. In mammals, apoptosis can be initiated by three different pathways: (1) the extrinsic pathways, which can be triggered by ligation of death receptors and subsequent Caspase- 8 activation; (2) the intrinsic pathway, which is initiated by cellular stress followed by activation of caspase-9; or (3) the granzyme B pathway, where the cytotoxic cell protease granzyme B pathway is delivered to sensitive target cells. Each of these pathways converges to a common execution phase of apoptosis that requires proteolytic activation of caspase-3 and/ or -7 from their inactive zymogens [18].

Because of its fundamental importance, programmed cell death is a highly regulated pathway. One important set of proteins involved in the regulation of apoptosis in the BcL-2 family. Over 25 family BcL-2 family members have been identified [19]. These can be broadly divided into two classes: those that inhibit apoptosis and those promote apoptosis.

Due to their importance in keeping cancer cells alive, BcL-XL and BcL-2 are considered relevant targets for cancer chemotherapy. In fact, BcL-2 anti-sense nucleotides are currently being tested in clinical trials for treatment of cancer [20].

Our study aimed to investigate the potency of APPJ exposure to perturb genetic and cell cycle progression leading to a programmed death of the CML cells which resistant or partially responded to chemotherapy.

\section{Materials and Methods}

\section{Character of exposure machine}

Non-thermal plasmas are frequently called, "on-equilibrium” plasmas because they are characterized by a large difference in the temperature of the electrons relative to the ions and neutrals. Since the electrons are extremely light, they move quickly and have almost no heat capacity. In these plasmas, $\mathrm{Te}>>\mathrm{Ti} » \mathrm{Tn}$. Ionization is maintained by the impact of electrons (which may have temperatures ranging from 0.1 to more than $20 \mathrm{eV}$ ) with neutral species, producing additional electrons and ions. These plasmas are typically maintained by the passage of electrical current through a gas.

Cold APPJ devices have recently attracted significant attention [21]. The most important devices for generating atmospheric pressure nonthermal plasmas can be considered: APPJ [22], plasma needle [23], plasma pencil [24], miniature pulsed glow-discharge torch [25], one atmosphere uniform glow-discharge plasma [26], resistive barrier discharge [27] and dielectric barrier discharge [28].
A schematic of the pulsed APPJ discharge and of the experimental setup is shown in Figure 1. The gas is fed through an annular region between the two metal electrodes $15 \mathrm{~cm}$ in length. The inner electrode is $5 \mathrm{~mm}$ in diameter and is powered with pulsed high voltage power supply, while the grounded outer electrode is separated from the inner electrode by a gap of $2-3 \mathrm{~mm}$. A rotating spark gap is made by mounting the ground electrode on a rotating plane.

The APPJ device operates using $10-20 \mathrm{kV}$ power supply with a gap between two electrodes is 2-3 $\mathrm{mm}$ under atmospheric pressure [22]. The electrical discharge inside the reactor of APPJ was induced by a pulsed high voltage power supply. The discharge power was adjusted by the pulse voltage with a pulse frequency of $167 \mathrm{kHz}$.

\section{Chemicals}

The chemicals of the blood culture were purchased from GIBCOBRL, USA. Heat-inactivated fetal calf serum (FCS) from Sigma/Aldrich chemical Co, St Louis, USA,

\section{Blood sampling}

Blood samples obtained from six volunteers of CML patients, the first three of them were in AP-CML, and they were imatinib resistant (TRcase), and the others were in CP-CML, and they were partially responded to the imatinib treatment (T-case). The diagnosis was based on clinical examination and laboratory evaluation, which were carried out by the consultant medical staff.

Further, healthy subjects matched with patient groups for ethnic background, sex, smoking and age were also investigated as control group.

All the cases were clinically diagnosed with a medium duration 1-2 years at the accelerated phase. We chose three cases were responded to nilotinib and returned to the $\mathrm{CP}$ through one year but the others three cases were not responding through the same period of treatment and still persisted in AP. One patient from this group evolved to death.

The mean value of WBCs count for the T-group at the beginning of treatment was 80,000 cells $/ \mathrm{mm} 3$ and within 8 to 12 months through the nilotinib period reached to 8,000 cells $/ \mathrm{mm} 3$. In addition the Bcr-abl was decreased through the same period of the treatment with ratio (2.03:0.27) prior to sampling, whereas the TR-group recorded mean value of total leukocytes count at the beginning of the treatment was 118,000 cells $/ \mathrm{mm} 3$ and within one year of nilotinib treatment, the mean value was 90,000 cells/ $\mathrm{mm} 3$ (Bcr-abl ratio was 3.84: 2.03) accordingly they received interferon therapy at last three months prior to sample collection.

All subjects were gave an informed consent for participation in this study. The donors were selected according to current International Programme on Chemical Safety (IPCS) guidelines for the monitoring of genotoxic effects of carcinogens in human [29].

Venous blood were collected under sterile conditions in heparinized

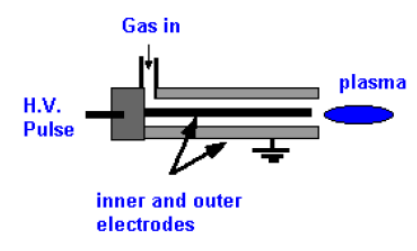

A

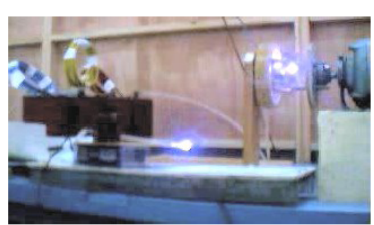

B
Figure 1: Schematic representation $(A)$ and photo $(B)$ of the designed APJJ device. 
Citation: Elhadary AMA, El-Aragi GM, Ahmed MM, Said ZS (2015) Assessment of Cytogenetic Instability and Gene Transcription of Chronic Myelogenous Leukemia Cells Exposed to Non-thermal Plasma. J Cytol Histol 6: 371. doi:10.4172/2157-7099.1000371

vacationer tube ( $\mathrm{v}=5 \mathrm{ml}$, Becton Dickinson, USA) containing Lithium heparin as anticoagulant.

\section{Experimental Design}

The blood from each volunteer was divided into four groups for each case (TR and T cases). One was non-exposed and the other three were applied directly to APPJ at a distance of $3 \mathrm{~cm}$ from the blood surface. In each group, three time period groups were selected for the study $(40,80$ and $120 \mathrm{sec}$.). The first four groups of TR-case were as a following: TR, TR-D1 (duration for $40 \mathrm{sec}$.), TR-D2 (duration for $80 \mathrm{sec}$.) and TR-D3 (duration for $120 \mathrm{sec}$.) groups. The other four groups of T-case were as a following: T, T-D1, T-D2, and T-D3 groups. All previous groups were matched with healthy subjects group, which represent the negative control (C-group).

The blood incubated at $37^{\circ} \mathrm{C}$ before initiation of cultures then cytogenetic analysis and gene transcriptions done for each group before and after exposure to APPJ.

\section{Blood culture}

Triple blood cultures were set up for 48 hours for each sample according to the protocol described by Evans and O' Riodran [30].

\section{Chromosomal aberration test}

The cells were cultured for 48 hours, blocked in metaphase, fixed, stained with Giemsa, and scored; at least 50 cells per slide were examined under 100X magnification for mitotic analysis. The number of total cells in the mitotic division was scored and the percentage of cell division was calculated (MI), percentage of mitotic phases, percentage and type of abnormalities in each mitotic phases. The most common abnormalities were pictured by microphotography. The cytogenetic analysis technique was done according to protocol recommended by $[16,31]$.

\section{P53 and Bcl2 Genes transcription and caspase-3 levels}

Analysis of gene transcriptions carried out using by ELISA kit according to the following kits:

1- P53 tumor protein (P53/Tp53), purchased by CUSABIO Company, Cat NO: CSB- E08336r.

2- Caspase 3 (Casp-3) purchased by CUSABIO Company, Cat No: CSB-E08857r, web: www.cusabio.com.

3- B-cell CLL/lymphoma2 (Bcl-2), purchased by MY BioSource company, Cat NO. MBS704498, Web: wwwmybiosource.com.

\section{Statistical analysis}

Data was presented as distribution analysis, percentages, means \pm
SE and analyzed using two ways analysis of variance " $F$ " test according to Abramowitz and Stegum [32], the level for statistical significance was $\mathrm{p}<0.05$.

\section{Results}

Table 1 showed that the mitotic index in TR group had a significant increase as 5.4 folds when compared with that of C-group. Whereas, exposed groups (TR-D1, TR-D2 and TR-D3) mitotic indices showed significant decreases when compared with that of the non-exposed group (TR). TR-D2 group scored the lowest value in mitotic index when compared with the other exposure doses. As well, mitotic index in TR-D3 group showed a significant decrease when compared with that of TR-D1.

On the other hand, a significant decrease in number of cells entered prophase in CML patients by 2.2 folds than that of C-group. However, exposed groups showed no significant differences in the frequency of prophase when compared with that of non-exposed group (Figure 2B).

A significant decrease in metaphase frequencies (normal mitotic pattern) was observed in TR-D2 and TR-D3 groups when compared to that of the other groups. The lowest number of metaphases was detected in TR-D3 group (Figure 2A).

TR-D1 and TR-D2 were recorded significant decrease in anaphase and telophase cells when compared with that of TR-group and C-group. In addition, a significant difference was scored in TR-D3 in comparing with that of TR-group.

As regard to mitotic abnormalities, induction of sticky cells was significantly increased in exposed groups when compared with TR- and C-group. The values of the frequencies of the sticky metaphases were scored with gradually increments from TR-D1 to TR-D3 (Figures 2C-2E). Moreover, condensed chromosome metaphases were detected with low frequency in the control group comparing with the other estimated groups (Figures 2D-2I). Whereas, the exposed groups (TR-D1, TR-D2 and TRD3) showed nearly or more than two folds increments in the condensed chromosome metaphases than that of non-exposed group (TR-group)

Figure 3 illustrated that the total number of metaphases in the normal and abnormal patterns were more arrested in the exposed groups than that of control and TR groups.

Table 2 showed that the T-group had a significant increase in mitotic index when compared with the C-group and no significant decrease was observed when compared with all exposed groups (T-D2 group had the lowest value of mitotic index).

The statistical differences between the means of the percentages of

\begin{tabular}{|c|c|c|c|c|c|}
\hline \multirow{2}{*}{ Group } & Mitotic index & Prophase & $\begin{array}{c}\text { Mitotic Phase } \\
\text { Metaphase } \\
\text { (Normal Pattern) }\end{array}$ & $\begin{array}{c}\text { Mnaphase\& Telophase } \\
\text { Anticky Chromosome } \\
\text { Metaphases }\end{array}$ & $\begin{array}{c}\text { Condensed } \\
\text { Chromosome } \\
\text { Metaphases }\end{array}$ \\
\hline C-group & $8.5 \pm 0.76$ & $17.33 \pm 0.5$ & $63.33 \pm 1.93$ & $17.0 \pm 2.22$ & $0.56 \pm 0.56$ \\
\hline TR-group & $45.60 \pm 2.28^{\mathrm{a}}$ & $7.75 \pm 1.14^{\mathrm{a}}$ & $65.81 \pm 2.47$ & $18.36 \pm 1.32$ & $2.69 \pm 0.65$ \\
\hline TR-D1 group & $34.13 \pm 1.14^{\mathrm{a}, \mathrm{b}}$ & $6.33 \pm 0.67^{\mathrm{a}}$ & $61.0 \pm 1.00$ & $10.11 \pm 0.68^{\mathrm{a}, \mathrm{b}}$ & $12.56 \pm 0.73^{\mathrm{a}, \mathrm{b}}$ \\
\hline TR-D2 group & $19.67 \pm 0.88^{\mathrm{a}, \mathrm{b}, \mathrm{b}}$ & $8.30 \pm 1.43^{\mathrm{a}}$ & $53.0 \pm 1.53^{\mathrm{a}, \mathrm{b}, \mathrm{c}}$ & $9.85 \pm 1.17^{\mathrm{a}, \mathrm{b}}$ & $10.0 \pm 1.53^{\mathrm{a}, \mathrm{b}}$ \\
\hline TR-D3 group & $25.97 \pm 1.18^{\mathrm{a}, \mathrm{b}, \mathrm{b}, \mathrm{d}}$ & $7.04 \pm 0.58^{\mathrm{a}}$ & $40.26 \pm 2.67^{\mathrm{a}, \mathrm{b}, \mathrm{c}, \mathrm{d}}$ & $11.37 \pm 1.89^{\mathrm{b}}$ & $26.30 \pm 0.89^{\mathrm{a}, \mathrm{b}, \mathrm{c}, \mathrm{d}}$ \\
\hline
\end{tabular}

${ }^{*} \mathrm{P}<0.05$

a: P-value Significant when compared with C- group.

b: P-value Significant when compared with TR-group.

c: P-value Significant when compared with TR-D1group.

d: P-value Significant when compared with TR-D2group.

Table 1: Mitotic index, phase and abnormalities in exposed and non-exposed TR-and control groups (Means \pm SE) 
Citation: Elhadary AMA, El-Aragi GM, Ahmed MM, Said ZS (2015) Assessment of Cytogenetic Instability and Gene Transcription of Chronic Myelogenous Leukemia Cells Exposed to Non-thermal Plasma. J Cytol Histol 6: 371. doi:10.4172/2157-7099.1000371
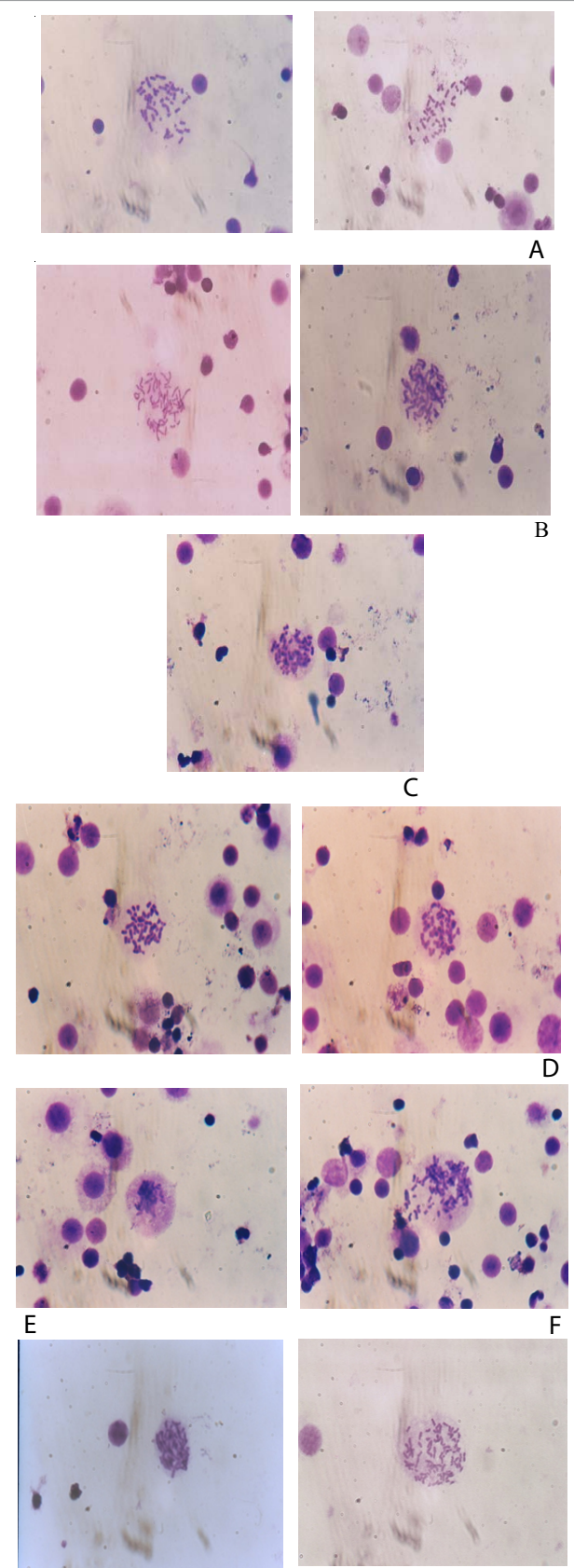

G

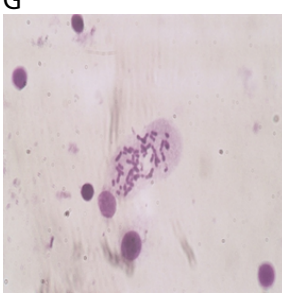

$\mathrm{H}$

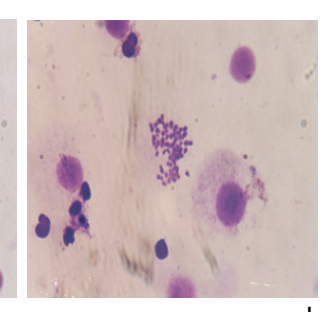

Figure 2: Normal and abnormal mitotic patterns of exposed and non-exposed TR- and T- groups: A) Normal pattern of metaphase. B) Prophase. C) Sticky metaphase with laggard chromosomes. D) Sticky metaphase with condensed chromosomes. E) Sticky metaphase with mitotic failure. F) Sticky and failure of chromosomes segregation in anaphase. G) Mitotic disruption with failure of assembly of spindle apparatus. $\mathrm{H}$ ) Failure of segregation into two chromatids, each pole receives only one set of chromosomes. I) Metaphase with condensed chromosomes.

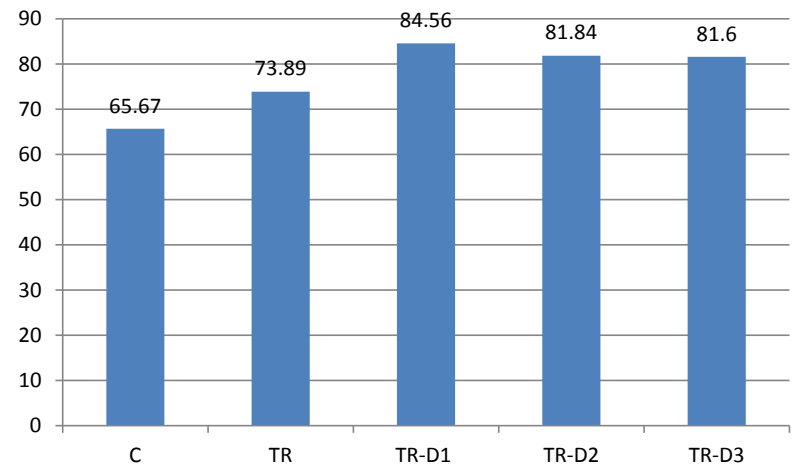

Figure 3: Total numbers of normal and abnormal metaphases in exposed and non-exposed TR-group.

prophase of all groups were not significant except that of T-D1 group when compared with $\mathrm{C}$ and T-groups. Metaphases data recorded significant decreases in T-D1, T-D2 and T-D3 groups when compared with $\mathrm{C}$ and T-groups. T-D2 group evidenced the lowest rate in metaphase frequencies. In addition, anaphase and telophase frequencies stated no significant differences between T-D1 and T-D2 groups and C-group. Contrary, significant differences were observed between T-D1, T-D2 and T-D3 groups and T-group.

The means of percentages of mitotic abnormalities were indicated in T-group as the following: significant increase of sticky and condensed chromosome metaphases in exposed and non-exposed groups when compared with C-group. In addition, there are significant increases of sticky cells in T-D1, T-D2 and T-D3 groups more than T-group; particularly T-D2 group had the highest frequency of sticky cells. On the other hand, for condensed chromosome metaphases the exposed groups were significantly less than T-group except T-D3 group, which recorded non-significant value higher than T-group.

The total number of normal and abnormal patterns of the metaphases in the non-exposed and exposed groups was more than that of the control group. Whereas, T-D2 group scored the lowest values in the two metaphases patterns (Figure 4).

As regard to $\mathrm{P} 53$ and Bcl-2 genes transcriptional levels, Table 3 showed that TR-group had high significant incidences when compared with control group. P53 level scored significant increase in the exposed groups when compared with TR group. The remarkable increment was observed in TR-D2 group more than the other exposed groups. In the meantime, the transcriptional levels of $\mathrm{Bcl}-2$ genes were significantly decreased in exposed groups when compared with TR-group. However, TR-D3 group revealed higher level in this gene expression comparing with that of control, TR-D1 and TR-D2 groups.

As for caspase-3, its levels were detected with lower values in exposed and non-exposed groups comparing with that of the control group. Whereas, its values were increased in TR-D1 and TR-D2 groups more than that of TR- group. While, TR-D3 was recorded with slightly decreased value comparing with TR-group.

Table 4 showed that the non-exposed T- group and exposed groups showed significant increase in level of p35 when compared with that of control group. Moreover, P53 levels were remarkably increased in TD-2 and T-D3 when compared with that of non-exposed group. The data of caspase-3 was showed non- significant increase in T-D1 and T-D2 when compared with T-group but T-D3 insignificantly decreased. Moreover, the caspase-3 levels in the exposed groups were non-significantly different when compared with control group. 
Citation: Elhadary AMA, El-Aragi GM, Ahmed MM, Said ZS (2015) Assessment of Cytogenetic Instability and Gene Transcription of Chronic Myelogenous Leukemia Cells Exposed to Non-thermal Plasma. J Cytol Histol 6: 371. doi:10.4172/2157-7099.1000371

Page 5 of 8

\begin{tabular}{|c|c|c|c|c|c|c|}
\hline \multirow{2}{*}{ Group } & Mitotic index & Prophase & $\begin{array}{c}\text { Metaphase } \\
\text { (Normal Pattern) }\end{array}$ & $\begin{array}{c}\text { Anaphase \& } \\
\text { Telophase }\end{array}$ & $\begin{array}{c}\text { Sticky Chromosome } \\
\text { Metaphases }\end{array}$ & $\begin{array}{c}\text { Condensed Chromosome } \\
\text { Metaphases }\end{array}$ \\
\cline { 3 - 6 } C-group & $8.5 \pm 0.76$ & $17.33 \pm 0.51$ & $63.33 \pm 1.93$ & $17.0 \pm 2.22$ & $0.56 \pm 0.56$ \\
\hline T-group & $15.67 \pm 1.20^{\mathrm{a}}$ & $16.0 \pm 1.53$ & $56.67 \pm 1.45$ & $5.67 \pm 0.33^{\mathrm{a}}$ & \\
\hline T-D1 group & $13.33 \pm 1.20^{\mathrm{a}}$ & $10.0 \pm 0.58^{\mathrm{a}, \mathrm{B}}$ & $49.67 \pm 0.33^{\mathrm{a}, \mathrm{B}}$ & $10.11 \pm 0.68^{\mathrm{B}}$ & $17.33 \pm 1.45^{\mathrm{a}}$ \\
\hline T-D2 group & $9.33 \pm 0.33^{\mathrm{B}, \mathrm{C}}$ & $16.0 \pm 0.58^{\mathrm{C}}$ & $41.0 \pm 0.58^{\mathrm{a}, \mathrm{B}, \mathrm{C}}$ & $18.0 \pm 1.16^{\mathrm{B}}$ & $15.33 \pm 0.88^{\mathrm{a}, \mathrm{B}}$ \\
\hline T-D3 group & $10.0 \pm 0.58^{\mathrm{B}}$ & $13.33 \pm 0.88^{\mathrm{C}}$ & $44.0 \pm 0.58^{\mathrm{a}, \mathrm{B}, \mathrm{C}, \mathrm{D}}$ & $8.0 \pm 0.58^{\mathrm{a}, \mathrm{B}, \mathrm{C}, \mathrm{D}}$ & $18.0 \pm 0.58^{\mathrm{a}, \mathrm{B}}$ \\
\hline
\end{tabular}

\section{${ }^{*} P<0.05$}

B: P-value Significant when compared with T-group.

C: P-value Significant when compared with T-D1group.

D: P-value Significant when compared with T-D2group.

Table 2: Mitotic phase, index and abnormalities in exposed and non-exposed T- and control groups (Means \pm SE)

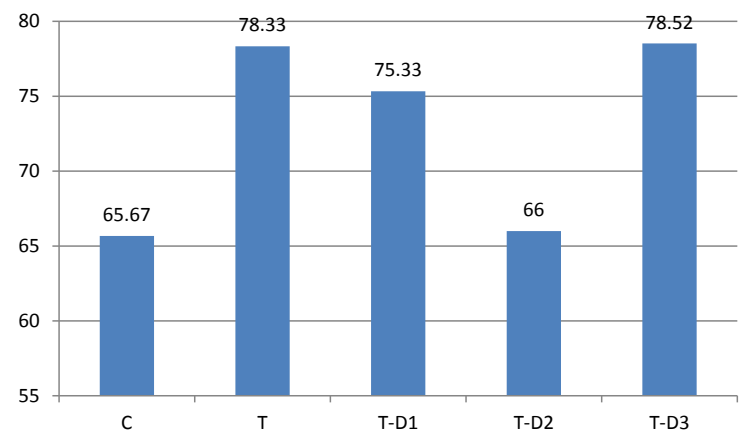

Figure 4: Total numbers of normal and abnormal metaphases in exposed and non-exposed T-group.

\begin{tabular}{|c|c|c|c|}
\hline Group & P53 $\mathbf{~ g g / m l}$ & Caspase-3 $\mathbf{~ g / m l}$ & BCL-2 $\mathbf{~ n g / m l}$ \\
\hline C-group & $8.57 \pm 0.09$ & $1.86 \pm 0.17$ & $0.62 \pm 0.10$ \\
\hline TR-group & $41.18 \pm 0.49^{\mathrm{a}}$ & $1.35 \pm 0.23$ & $1.02 \pm 0.04^{\mathrm{a}}$ \\
\hline TR-D1 group & $56.02 \pm 1.53^{\mathrm{a}, \mathrm{b}}$ & $1.41 \pm 0.12$ & $0.60 \pm 0.10^{\mathrm{b}}$ \\
\hline TR-D2 group & $74.07 \pm 2.29^{\mathrm{a}, \mathrm{b}, \mathrm{c}}$ & $1.66 \pm 0.096$ & $0.55 \pm 0.17^{\mathrm{b}}$ \\
\hline TR-D3 group & $57.90 \pm 1.04^{\mathrm{a}, \mathrm{b}, \mathrm{d}}$ & $1.2 \pm 0.08^{\mathrm{a}, \mathrm{d}}$ & $0.72 \pm 0.08^{\mathrm{b}}$ \\
\hline
\end{tabular}

${ }^{*} \mathrm{P}<0.05$

a: P-value Significant when compared with C- group.

b: P-value Significant when compared with TR-group.

c: P-value Significant when compared with TR-D1 group.

d: P-value Significant when compared with TR-D2 group.

Table 3: Transcriptional levels of P53, Caspase-3 and BCL-2 genes in exposed and non-exposed TR- and control group

\begin{tabular}{|c|c|c|c|}
\hline Group & $\mathbf{P 5 3} \mathbf{~ p g / m \mathbf { ~ }}$ & Caspase-3 $\mathbf{~ g / m l}$ & $\mathbf{B C L - 2} \mathbf{~ n g} / \mathbf{m l}$ \\
\hline C-group & $8.57 \pm 0.09$ & $1.86 \pm 0.17$ & $0.62 \pm 0.10$ \\
\hline T-group & $30.30 \pm 0.64^{\mathrm{a}}$ & $1.51 \pm 0.11$ & $0.83 \pm 0.12$ \\
\hline T-D1 group & $32.35 \pm 1.27^{\mathrm{a}}$ & $1.65 \pm 0.08$ & $0.58 \pm 0.08$ \\
\hline T-D2 group & $39.08 \pm 1.15^{\mathrm{a}, \mathrm{B}, \mathrm{C}}$ & $1.81 \pm 0.09$ & $0.11 \pm 0.05^{\mathrm{a}, \mathrm{B}, \mathrm{C}}$ \\
\hline T-D3 group & $62.86 \pm 1.08^{\mathrm{a}, \mathrm{B}, \mathrm{C}, \mathrm{D}}$ & $1.31 \pm 0.16^{\mathrm{D}}$ & $0.81 \pm 0.13^{\mathrm{a}, \mathrm{D}}$ \\
\hline
\end{tabular}

${ }^{*} \mathrm{P}<0.05$

B: P-value Significant when compared with T-group.

C: P-value Significant when compared with T-D1 group.

D: P-value Significant when compared with T-D2 group.

Table 4: Transcriptional levels of P53, Caspase-3 and BCL-2 genes in exposed and non-exposed T- and control group
For T-D2 group, there is notable decrement of Bcl-2 gene transcription level when compared with T-group rather than the other exposed groups, which recorded non-significant decrement.

\section{Discussion}

Our somatic cells are born by mitosis and almost all will die by apoptosis, a physiological process of cellular suicide. Cancers can occur when this balance is disturbed, either by an increase in cell proliferation or a decrease in cell death. The goal of cancer therapy is to promote the death of cancer cells without causing too much damage to normal cells [33].

Imatinib mesylate (Gleevec, Novartis Pharma, New Jersey, USA) is a first-generation tyrosine kinase inhibitor (TKI) that was approved for frontline therapy in patients with (CML) by the US Food and Drug Administration (FDA) in 2002. It is dosed at $400 \mathrm{mg}$ daily in patients with CML in the CP-CML and $600 \mathrm{mg}$ daily in patients with -AP-CML and for those in the blast phase (CML-BP). Imatinib mesylate is a BCR-ABL-targeted therapy and considered the standard of care in CML management [34].

Despite the positive results obtained in previous studies, approximately $33 \%$ of patients with CML treated with imatinib do not achieve a complete cytogenetic response, while others have drug resistance or cannot tolerate drug-related toxicities [35].

On the other hand, BCR-ABL kinase domain mutations may confer more specific resistance to nilotinib which will predominantly affect response rates, the presence of additional chromosomal aberrations may reflect genetic instability and, therefore, intrinsic aggressiveness of the disease which will be less amenable to subsequent alternative treatments and thus negatively affect overall survival [36].

Sensenig et al. [37] stated that apoptosis, or programmed cell death is a critical element of cellular self-regulation, which is a vital function in multicellular organisms allowing for appropriate growth, development, and death at the necessary times. The non-functioning of a tumor-suppressor gene or the over expression of an anti-apoptotic protein are both important pathways in cancer development.

Plasma is an ionized gas composed of charged particles (electrons, ions), electronically excited atoms and molecules, radicals, and UV photons. Plasma treatment exposes cells or tissue surface to active short- 
Citation: Elhadary AMA, El-Aragi GM, Ahmed MM, Said ZS (2015) Assessment of Cytogenetic Instability and Gene Transcription of Chronic Myelogenous Leukemia Cells Exposed to Non-thermal Plasma. J Cytol Histol 6: 371. doi:10.4172/2157-7099.1000371

and long-lived neutral atoms and molecules, including ozone $\left(\mathrm{O}_{3}, \mathrm{NO}, \mathrm{OH}\right.$ radicals, and singlet oxygen $\left(\mathrm{O}_{2}\right)$, and a significant flux of charged particles, including both electrons and positive and negative ions like super oxide radicals [38].

Mitosis process follows five stages and is terminated by cytokinesis. The cells should pass through two checkpoints before entering into mitosis. First is the G2 checkpoint in response to DNA damage, [39], followed by the antephase checkpoint that is activated to prevent mitotic defects in response to a number of stresses, changes in chromatin structure and spindle damage (Figures $2 \mathrm{~F}$ and $2 \mathrm{G}$ ) before the cells reach the point of 'no-return' [40]. The antephase checkpoint which was first introduced by Bullough and Johnson [41] exists between the G2 and early prophase [42].

Our findings showed that the treatment resistant group (TR) exhibited a significant increase rate of mitotic index more than control group (5.4 folds). After APPJ exposure with the three doses (TR-D1, TR-D2 and TRD3), the mitotic indices decreased significantly remarkably with TR-D2 (Table 1). At the same current, the treatment responded group (T) was significantly increased in the rate of mitotic index more than that of control group (1.8 folds). However, there is non-significant decrease of the mitotic indices rates between T-group before and after plasma exposure. T-D2 group scored the lowest value of mitotic index comparing with the other exposure doses (Table 2).

This depression in mitotic indices which occurred after exposure to APPJ may be attributed to the check points which enforce the correct sequence of events after DNA or spindle damage this mechanisms arrest cell cycle progression in response to damage. DNA damage sent negative signals to a series of protein kinases, which arrest the cycle at DNA damage checkpoint [43].

Light microscopy cells were well preserved at all time intervals studied. General observations on nuclear morphology and mitotic phases are summarized in Tables 1 and 2. All mitotic phases were represented in dividing cells, providing a basis for comparison with treated samples. Mitotic prophase required chromosome condensation and a visible nuclear membrane. Metaphase required near linear alignment of chromatids on one or more equatorial planes and no visible nuclear membrane. Anaphase was scored when chromatids were condensed, were segregated into two or more groups, and were not arranged in linear arrays. All anaphase nuclei lacking this feature were scored as abnormal. Telophases required complete segregation of chromatid clusters, early dispersion of chromatin material, and evidence of nuclear membrane reformation with or without evidence of cytokinesis [44].

In the present study, prophase scored in control group were significantly increased more than that of both non-exposed and exposed groups, but the frequencies of metaphases, anaphases and telophases in the TR-group were non-significantly increased than that of C-group.

Metaphases with normal pattern recorded in TR-D1, TR-D2 and TRD3 groups were decreased than that of TR-group. On the other hand, the total frequencies of the metaphases with normal and abnormal patterns were lower than that of TR-group (Figures 2 and 3). After APPJ exposure, Anaphase \& telophase were expressed lower frequencies in exposed groups than that of non-exposed and control groups.

The accumulation of normal and abnormal patterns of metaphases after plasma exposure may be discussed in view of the inability of the cells to perform metaphase checkpoint, by stabilizing activity of mitotic cyclin dependent kinases and preventing cells to exit from mitosis [45]. Thus, the presented data confirm that both entry into and exit from mitosis is blocked in treated cells suggesting that plasma exposure may interfere with the balance between cyclin condensation required for participation into mitosis and its ubiquitinous destruction by anaphase promoting complex [46].

Another interpretation presented by Shah and Cleveland [47] in their study were most microtubule- damaging agents that inhibit normal spindle formation, either by increasing microtubule stability or by depolymerization, conduced cells to arrest at metaphase-to-anaphase transition by the action of the spindle- attachment checkpoints.

In contrary, the presented data (Table 2 and Figures 2 and 4) for the treated cases which responded to the chemotherapy but with severe depletion in the total leukocytic counts. The exposure to the APPJ improves the mitotic index and the ratio between the different phases. Therefore, there are not significant differences between exposed and non-exposed groups and control group for most percentages of the phase's data.

The most effective role of the exposure of CML cells to the plasma through its division is the expression of abnormal pattern of metaphases (sticky and condensed chromosome metaphases), which take its paths to apoptosis and necrosis. Our findings as presented in Table 1. pointed to highly significant increment in the number of metaphases with sticky chromosomes in the exposed groups (TR-D1, TR-D2 and TR-D3 groups) comparing with non-exposed (TR- group) and control groups. Moreover, the same event occurred for the appearance of condensed chromosome metaphases after APPJ exposure.

Table 2 showed that there are highly increment for sticky and condensed chromosome metaphases in the exposed group (T-D1, T-D2 and T-D3 groups) comparing with non exposed and control groups but this increment were less than their data that investigated for the exposed TR-group.

Sticky chromosomes or metaphases and condensed chromosomes which be detected in this study, after APPJ exposure, considered the main observed abnormalities due to cell cycle and spindle check points. Babich et al. [48] reported that metaphases with sticky chromosomes lose their normal appearance and appear to have a sticky "surface" which causes chromosome agglomeration, possibly due to effects on chromatin and chromosome organization.

Moreover, Erenpreisa et al. [49] stated that the increase of mitotic index in response to heat shock represented mostly an arrest in mitosis. The morphology and the increased ratio between metaphases and anaphases + telophases evidenced that this was arrest in metaphase, thus at a spindle checkpoint. A large portion of this delay looked like pyknotic metaphases, which shared morphological features with apoptosis. They contained sticky chromosomes, which tended to clump, a property dependent on DNA strand-breaks.

The cytogenetic findings in our work interpreted and concomitant with data of the apoptic gene transcription and caspases activation, which detected in CML cells before and after APPJ exposure. Tables 3 and 4 illustrated that the increments of transcriptional level of P53 in TR- and T-groups comparing with control group were inadequate for controlling the mitotic abnormalities and apoptic expression. After exposure to plasma, the data showed notable increases in P53 expression especially in the exposed TR-group and chiefly for 80 and 120 sec. periods.

Banin et al. [50] stated that plasma-jet treatment increased the level of phospho-p53. The tumor suppressor protein $\mathrm{p} 53$ plays a major role in the cellular response to DNA damage and other genomic aberrations. In response to cellular stresses including DNA damage, phosphorlylationmediated activation of $\mathrm{p} 53$ plays important roles in cell survival. Activation of p53 can lead to cell cycle checkpoint arrest and apoptosis by activating transcription of many downstream target genes. 
Citation: Elhadary AMA, El-Aragi GM, Ahmed MM, Said ZS (2015) Assessment of Cytogenetic Instability and Gene Transcription of Chronic Myelogenous Leukemia Cells Exposed to Non-thermal Plasma. J Cytol Histol 6: 371. doi:10.4172/2157-7099.1000371

Page 7 of 8

The levels of caspases- 3 in T and TR-groups were lower than that of the control group other than; there are gradually increasing in these levels after APPJ exposure, except for TR-D3 and T-D3 groups.

Caspases have been divided into two groups: initiators and effectors, first group of iniator (or apical) caspases (caspase-2, -8, -9, -10, and probably,-11). The effectors (or downstream) caspases are able to directly degrade multiple substrates including the structural and regulatory proteins in the cell nucleus, cytoplasm, and cytoskeleton [51]. Caspase-3, -6 , and -7 are three effectors caspases highly homologous to each other [52]. Their final functions are also similar or in executing apoptosis. In apoptic cells, caspase- 3 is the main executioner as it can be activated through both extrinsic and intrinsic signaling pathway, but it cannot be cleaved caspase-2 [53]. So, activation of the effector caspase-3 occurs as a last step of the apoptotic caspases cascade and is therefore considered as a late apoptotic signal. Plasma treatment induced activation of caspase- 3 in response to DNA damage [54].

The transcriptional levels of $\mathrm{Bcl}-2$ in TR- and T-groups were significantly and non-significantly higher than that of the control group respectively. But, there are gradually decreasing in these levels after APPJ exposure, except for TR-D3 and T-D3 groups.

Bcl-2 has not only been localized to the outer mitochondrial membrane but also to the nuclear envelope and the endoplasmic reticulum membrane (ER). In the ER, it regulates calcium storage, whose intracellular levels have been shown to affect apoptosis. ER-associated Bcl-2 is able to protect from apoptosis induced by various triggers. Beyond Bcl-2, Bcl-XL also interacts with pro-apoptotic members like BAX and BAK thought their $\mathrm{BH} 3$ domains [55]. It is possible that the anti-apoptotic action of $\mathrm{Bcl}-2$ and $\mathrm{Bcl}-\mathrm{XL}$ is converted to a pro-apoptotic one when these proteins are cleaved by caspases after initiation of apoptosis [56].

The mechanism of action of cold plasma on cancer cells is related to generation of reactive oxygen species with possible induction of apoptosis pathway, and the cancer cells are more susceptible to the effects of cold atmospheric plasma because a greater percentage of cells are in S-phase of the cell cycle [57]. When leukemia cells were treated with the cold plasma plume, the scientists found something unexpected: The cells did not die right away. Rather, right after experiment in the zero th hour, the cells are still okay. But after four to eight hours, they start dying "Said Laroussi" [58].

In summary, we investigated the feasibility of APPJ treatment for CML therapy and examined the mechanism by which plasma induces antiproliferative properties and apoptosis. This effect occurred through not only the decreasing of mitotic index and increased metaphases arrest, but also through the increment of p53 transcription levels, activated caspase- 3 and downstream of Bcl-2.

The presented study is the third part of our work on CML investigation and treatment by APPJ exposure. In addition, the period time of $80 \mathrm{sec}$. was the most effective and save dose for attendant with the advice of Ahmed et al. [59-61].

\section{Acknowledgment}

The authors greatly appreciate Dr. Hend El-Lithy, Clinical Hematology \& Internal medicine Dept., Kasr Al Ainy Hosp., Cairo University, for helping in medical consultant, providing facilities and blood sampling of this work.

\section{Declaration of interest}

The authors report no conflicts of interest. The authors alone are responsible for the content and writing of the paper.

\section{References}

1. Stroth U, Phänomene, Grundlagen, Anwendungen (2011) Plasmaphysik. 1 (1stedn). Vieweg \& Teubner Verlag, Springer Fachmedien Wiesbaden $\mathrm{GmbH}$ Wiesbaden 488.

2. Weltmann KD, Polak M, Masur K, von Woedtke T, Winter J, et al. (2012) Plasma processes and plasma sources in medicine. Contrib Plasma Phys 52: 644-54.

3. Klaus-Dieter W, Thomas VW (2011) Basic requirements for plasma sources in medicine. The European Physical J Applied physics 55: 1

4. Shashurin A, Keidar M, Bronnikov S, Jurjus RA, Stepp MA (2008) Living tissue under treatment of cold plasma atmospheric jet. Applied Physics Letters 93: 181501.

5. Lupu AR, Georgescu N, Calugau A, Cremer L, Szegli G, et al. (2009) The effects of cold atmospheric plasma jets on B16 and COLO320 tumoral cells. Roum Arch Microbiol Immunol 68: 136-144.

6. Perrotti D, Jamieson C, Goldman J, Skorski T (2010) Chronic myeloid leukemia mechanisms of blastic transformation. J Clin Invest 120: 2254-2264.

7. Shah NP, Nicoll JM, Nagar B, Gorre ME, Paquette RL, et al. (2002) Multiple $\mathrm{BCR}-\mathrm{ABL}$ kinase domain mutations confer polyclonal resistance to the tyrosine kinase inhibitor imatinib (STI571) in chronic phase and blast crisis chronic myeloid leukemia. Cancer Cell 2: 117-125.

8. Venkitaraman AR (2007) Chromosomal instability in cancer: causality and interdependence. Cell Cycle 6: 2341-2343.

9. Nakanishi M, Shimada M, Niida H (2006) Genetic instability in cancer cells by impaired cell cycle checkpoints. Cancer Sci 97: 984-989.

10. Mateuca R, Lombaert N, Aka PV, Decordier I, Kirsch-Volders M (2006) Chromosomal changes: induction, detection methods and applicability in human biomonitoring. Biochimie 88: 1515-1531.

11. Ruth NM, Lynda JC (2011) The role of dicentric chromosome formation and secondary centromere deletion in the evolution of myeloid malignancy. Genetics Research International. Article ID 643628, 11 pages.

12. Rudolph P, Peters J, Lorenz D, Schmidt D, Parwaresch R (1998) Correlation between mitotic and $\mathrm{Ki}-67$ labeling indices in paraffin-embedded carcinoma specimens. Hum Pathol 29: 1216-1222.

13. Bucher N, Britten CD (2008) G2 checkpoint abrogation and checkpoint kinase-1 targeting in the treatment of cancer. $\mathrm{Br} \mathrm{J}$ Cancer 98: 523-528.

14. Vitale I, Galluzzi L, Castedo M, Kroemer G (2011) Mitotic catastrophe: a mechanism for avoiding genomic instability. Nat Rev Mol Cell Biol 12: 385-392.

15. Touati SA, Cladière D, Lister LM, Leontiou I, Chambon JP, et al. (2012) Cyclin A2 is required for sister chromatid segregation, but not separase control, in mouse oocyte meiosis. Cell Rep 2: 1077-1087.

16. Stevens JB, Abdallah BY, Regan SM, Liu G, Bremer SW, et al. (2010) Comparison of mitotic cell death by chromosome fragmentation to premature chromosome condensation. Mol Cytogenet 3: 20.

17. Kerr JF, Wyllie AH, Currie AR (1972) Apoptosis: a basic biological phenomenon with wide-ranging implications in tissue kinetics. Br J Cancer 26: 239-257.

18. Salvesen GS, Dixit VM (1997) Caspases: intracellular signaling by proteolysis. Cell 91: 443-446.

19. Adams JM, Cory S (1998) The Bcl-2 protein family: arbiters of cell survival. Science 281: 1322-1326

20. Wang JL, Liu D, Zhang ZJ, Shan S, Han X, et al. (2000) Structure-based discovery of an organic compound that binds $\mathrm{Bcl}-2$ protein and induces apoptosis of tumor cells. Proc Natl Acad Sci U S A 97: 7124-7129.

21. Li G, Li H, Wang L, Wang S, Zhao H, et al. (2008) Genetic effects of radiofrequency, atmospheric pressure glow discharges with helium. Applied Physics Letters 92: 221504.

22. Niemi K, Wang Sh, Schultz-von, der Gathen V, Dbolele HF (2003) The Atmospheric-pressure Plasma Jet A Review and Comparison to Other Plasma Sources. Poster Conference Frontiers on Low temperature Plasma Diagnosis, Lecce Italy.

23. Stoffels E, Flikweert AJ, Stoffels WW. Kroesen GMW (2002) Plasma needle: a non-destructive atmospheric plasma source for fine surface treatment of (bio) materials. Plasma Sources Sci Technol 11: 383. 
Citation: Elhadary AMA, El-Aragi GM, Ahmed MM, Said ZS (2015) Assessment of Cytogenetic Instability and Gene Transcription of Chronic Myelogenous Leukemia Cells Exposed to Non-thermal Plasma. J Cytol Histol 6: 371. doi:10.4172/2157-7099.1000371

24. Laroussi M, Tendero C, Lu X, Alla S, Hynes WL (2006) Inactivation of bacteria by the plasma pencil. Plasma Process. Polym 3: 470.

25. Leveille V, Coulombe S (2005) Design and preliminary characterization of a miniature pulsed RFAPGD torch with downstream injection of the source of reactive species. Plasma Sources Sci Technol 14: 467.

26. Roth JR, Sherman DM, Ben Gadri R, Karakaya F, Chen Z, et al. (2001) A remote exposure reactor for plasma processing and sterilization by plasma active species at one atmosphere IEEE Trans. Plasma Sci 28: 56

27. Laroussi M, Alexeff I, Richardson JP, Dyer FF (2002) The resistive barrier discharge. IEEE Transactions on Plasma Science 30: 158-159.

28. Kanazawa S, Gogoma M, Moriwaki T, Okazaki S (1988) Organic thin film deposition in atmospheric pressure glow discharge. Appl Phs JD Appl Phys 21: 838.

29. Albertini RJ, Anderson D, Douglas GR, Hagmar L, Hemminki K, et al. (2000) IPCS guidelines for the monitoring of genotoxic effects of carcinogens in humans. International Programme on Chemical Safety. Mutat Res 463: 111172.

30. Evans HJ, O'Riordan ML (1975) Human peripheral blood lymphocytes for the analysis of chromosome aberrations in mutagen tests. Mutat Res 31: 135-148.

31. IAEA (2001) Cytogenetic analysis for radiation dose assessment. In: IAEA (Eds.), International Atomic Energy Agency, Technical Report Series 405. IAEA Vienna P: 138.

32. Abramowitz M, Stegun IA (1972) Handbook of mathematical functions. Dover Publications, Inc. New York, USA

33. Gerl R, Vaux DL (2005) Apoptosis in the development and treatment of cancer Carcinogenesis 26: 263-270.

34. Bhamidipati PK, Kantarjian H, Cortes J, Cornelison AM, Jabbour E (2013) Management of imatinib-resistant patients with chronic myeloid leukemia. Ther Adv Hematol 4: 103-117.

35. Kantarjian H, Hochhaus A, Saglio G, Souza C, Flinn I, et al. (2011) Nilotinib versus imatinib for the treatment of patients with newly diagnosed chronic phase, Philadelphia chromosome-positive, chronic myeloid leukaemia: 24-month minimum follow-up of the phase 3 randomised ENESTnd trial. Lancet Oncol 12: 841-851.

36. Kim TD, Türkmen S, Schwarz M, Koca G, Nogai H, et al (2009) Impact of additional chromosomal aberrations and BCR-ABL kinase domain mutations on the response to nilotinib in Philadelphia chromosome-positive chronic myeloid leukemia. Haematologica 95: 582-588.

37. Sensenig R, Kalghatgi S, Cerchar E, Fridman G, Shereshevsky A, et al. (2013) Non-thermal Plasma Induces Apoptosis in Melanoma Cells via Production of Intracellular Reactive Oxygen Species. Ann Biomed Eng 39: 674-87.

38. Fridman A, Chirokov A, Gutsol A (2005) Non-thermal atmospheric pressure discharges. J Phys D: Appl Phys 38: R1-R24.

39. Harper JW, Elledge SJ (2007) The DNA damage response: ten years after. Mol Cell 28: 739-745.

40. Chin CF, Yeong FM (2010) Safeguarding entry into mitosis: the antephase checkpoint. Mol Cell Biol 30: 22-32.

41. Bullough WS, Johnson M (1951) The energy relations of mitotic activity in adult mouse epidermis. Proc R Soc Lond B Biol Sci 138: 562-575.

42. Matsusaka T, Pines J (2004) Chfr acts with the p38 stress kinases to block entry to mitosis in mammalian cells. J Cell Biol 166: 507-516.
43. Park JW, Choi YJ, Jang MA, Baek SH, Lim JH, et al. (2001) Arsenic trioxide induces G2/M growth arrest and apoptosis after caspase-3 activation and bcl-2 phosphorylation in promonocytic U937 cells. Biochem Biophys Res Commun 286: 726-734.

44. Mackey MA, Morgan WF, Dewey WC (1988) Nuclear fragmentation and premature chromosome condensation induced by heat shock in S-phase Chinese hamster ovary cells. Cancer Res 48: 6478-6483.

45. Murray A (1995) Cyclin ubiquitination: the destructive end of mitosis. Cell 81 $149-152$.

46. Morgan DO (1997) Cyclin-dependent kinases: engines, clocks, and microprocessors. Annu Rev Cell Dev Biol 13: 261-291.

47. Shah JV, Cleveland DW (2000) Waiting for anaphase: Mad2 and the spindle assembly checkpoint. Cell 103: 997-1000.

48. Babich H, Segall MA, Fox KD (1997) The Allium test: A simple eukaryote genotoxicity assay. Am Bion Teach 59: 580-583.

49. Erenpreisa JE, Ivanov A, Dekena G, Vitina A, Krampe R, et al. (2000) Arrest in metaphase and anatomy of mitotic catastrophe: mild heat shock in two human osteosarcoma cell lines. Cell Biol Int 24: 61-70.

50. Banin S, Moyal L, Shieh S, Taya Y, Anderson CW, et al. (1998) Enhanced phosphorylation of p53 by ATM in response to DNA damage. Science 281 1674-1677.

51. Wang ZB, Liu YQ, Cui YF (2005) Pathways to caspase activation. Cell Biol Int 29: 489-496.

52. Degterev A, Boyce M, Yuan J (2003) A decade of caspases. Oncogene 22 8543-8567.

53. Porter AG, Jänicke RU (1999) Emerging roles of caspase-3 in apoptosis. Cell Death Differ 6: 99-104

54. Bundscherer L, Wende K, Ottmüller K, Barton A, Schmidt A, et al. (2013) Impact of non-thermal plasma treatment on MAPK signaling pathways of human immune cell lines. Immunobiology 218: 1248-1255.

55. Khemtémourian L, Sani MA, Bathany K, Gröbner G, Dufourc EJ (2006) Synthesis and secondary structure in membranes of the Bcl-2 anti-apoptotic domain BH4. J Pept Sci 12: 58-64.

56. Bellows DS, Chau BN, Lee P, Lazebnik Y, Burns WH, et al. (2000) Antiapoptotic herpesvirus $\mathrm{Bcl}-2$ homologs escape caspase-mediated conversion to proapoptotic proteins. J Virol 74: 5024-5031.

57. Keidar M, Shashurin A, Volotskova O, Stepp MA, Srinivasan P, et al. (2013) Cold atmospheric plasma in cancer therapy. Physics of plasmas 20: 057101.

58. Balch HB (2012) A low-temperature 'plasma blowtorch' triggers death of diseased cells. Inside Science News Service.

59. Ahmed MM, Aragi GM, El-Hadry AM, Montaser SA (2012) Cytogenetic and immunological effects on human blood cultures resulting from cold pulsed atmospheric pressure plasma jet exposure. Plasma Med 2: 191-205.

60. Ahmed MM, Said ZS, Montaser SA (2014) Chronic Myelogenous Leukemia: Cytogenetic and Biochemical Consequences and Applications for Diagnosis and Judgment. J Cytol Histol S4: 2, 1-8.

61. Ahmed MM, El-Aragi GM, Elhadary AMA, Said ZS (2013) Promising Trial for Treatment of Chronic Myelogenous Leukemia Using Plasma Technology Plasma Medicine 3: 311-334. 